By G. FLINT PURDY

\title{
Investigating Library Problems
}

In the following statement the librarian of Wayne University and editor of " $R e$ search and Experimentation" for this journal, points out why Waples" "Investigating Library Problems" is highly significant to librarianship.

W

HETHER or not we like the point of view for which it stands, or the form in which that point of view is presented, here is a little volume which none of us can afford to ignore-unless we believe the status quo in library service to represent perfection. If our libraries are not perfect-if our profession does not know everything about itself and its problems that is knowable, Investigating Library Problems ${ }^{1}$ has much of importance to offer us. That we have heretofore had in our professional literature not a single volume dealing with the principles involved in the systematic study of our problems must seem very strange to the student of other phases of the social structure. From our genesis we have been strangely aloof from introspection. The reasons are fairly apparent. We have not had much time for self-analysis. For half a century our energies were absorbed in developing methods for administering our geometrically growing collections and for making them available to a wide variety of users for a wide variety of purposes. The task was (and is) a difficult and complex one. In considerable measure we have succeeded. We are

${ }^{1}$ Waples, Douglas. Investigating Library Prob. lems. University of Chicago Press, 1939. undeniably excellent housekeepers. Furthermore, we have had, and still have, a great deal of missionary work to do. Not everyone recognizes the social importance of print and of its complete availability. Hence the emphasis, particularly of our colleagues in the public libraries, upon publicity.

Then, too, the picking-fly-specks-out-ofpepper type of "research" is a bit out of our line. We have always been largely literary folk, or bibliographers, or both. We have taken pride in the breadth of our learning, or in its depth in some particular field of scholarship. Few of us have had much contact with, or faith in, the so-called scientific method in its application to social phenomena. We have seen too many of the results of the positivistic logic of the nineteenth and twentieth centuries to be impressed with its omnipotence. It has occurred to us but recently, and been acknowledged reluctantly, that perhaps the method of science actually constitutes a tool of some value to us in the definition and solution of some of our problems.

Whatever the reasons, Professor Waples is the first to give us an introduction to research methodology written specifically for librarians. That at least four other books dealing with the same general subject are either in preparation or contemplated may be indicative of an important trend in librarianship. Perhaps, after a period of virtual stagnation, we are about to embark on a new and potentially fruit- 
ful course of action. After half a century of rapid progress we reached a plateau in many aspects of our development. Having remained on that plateau for more than a decade we are beginning to wonder where lies the road that leads beyond. We have reason to question the permanent and absolute validity of our old assumptions-hypotheses that have served us well, almost as well as Euclid's axioms for centuries served the mathematician.

Dr. Waples believes that some of our traditional assumptions have outlived their usefulness and are tending to promote stagnation, that in any case our professional structure is unlikely to be greatly expanded or improved on its present foundations. Whether or not we agree, there is only one answer. We must carefully and systematically inspect both foundations and superstructure, and render them termite proof. We are certain to find some shaky timbers. Indeed several have already been located and pointed out.

Investigating Library Problems is our first inspector's manual. It is a manual of the barest outline type, however-somewhat in the nature of a guide to the literature of research in librarianship. The author informs us in his preface that it is his purpose ". . merely to integrate the references by supplying connective tissue." It will therefore be useful to the practicing librarian primarily as a guide book rather than as a treatise on research methodology. It represents a first step, and an important one if for no other reason than that it is the first. Its somewhat vaguergroping, which will irritate many a librarian, is not primarily a result of Professor Waples' charming talent for writing completely around a point without quite touching it, but rather of the complex nature of the subject treated.
The difficulty of writing about research in library problems, and still more of actually investigating the problems, is one which we share with all students of social phenomena. This difficulty is implied in Waples' own words: "The assumptions which constitute library science are based on differences in publications, upon differences in readers' uses for publications, and upon the interrelations of the two." Thus we are dealing not only with the little understood complexities of print, but also with the less understood variables of human nature. Hence our problems are extremely difficult to investigate intelligently-but difficulty is not necessarily impossibility.

However, the complex nature of library problems emphasizes the importance of caution in their investigation, and particularly in the application of conclusions. There has been much stupidity, and not a little dishonesty, in social research, from which we may well profit. Both have resulted largely from impatience-from a very natural desire for answers, for prompt solutions to practical problems. The error is one which we are almost certain to duplicate in some degree. Its seriousness will be inversely proportional to the degree of intelligence and detachment which we can muster. The scientific method is slow, and it is not omnipotent. Intelligently employed, it is a useful tool.

It is our sincere hope that this journal will become a potent instrument for the stimulation and interpretation of research in those aspects of librarianship which fall within its province. To that end we hope to report on all such research concerning which we can procure information. Your cooperation in keeping us informed concerning all research projects, however unpretentious, is hereby solicited. 